\title{
Early blood pressure-independent cardiac changes in diabetic rats
}

\author{
Daniel Landau, Chen Chayat ${ }^{1}$, Nili Zucker, Eli Golomb ${ }^{2}$, Channa Yagil ${ }^{3}$, Yoram Yagil ${ }^{\mathbf{3}}$ and Yael Segev ${ }^{\mathbf{1}}$ \\ Department of Pediatrics A, Faculty of Health Sciences, Soroka University Medical Center, Ben Gurion University, PO Box 151, Beer Sheva 84101, Israel \\ ${ }^{1}$ Shraga Segal Department of Microbiology and Immunology, ${ }^{2}$ Department of Pathology and ${ }^{3}$ Laboratory for Molecular Medicine and Israeli Rat Genome Center, \\ Faculty of Health Sciences, Ben Gurion University, Beer Sheva 84105, Israel \\ (Correspondence should be addressed to D Landau; Email: Idaniel@bgu.ac.il)
}

\begin{abstract}
Cardiac remodeling is a key event in both diabetic and hypertensive heart diseases. In the present study, we investigated early myocardial changes in an animal model, the male Sabra rat model (SBH/y) of salt-induced hypertension-rendered diabetic with streptozotocin. Control non-diabetic (C), diabetic (D), and $\mathrm{D}$ or $\mathrm{C}$ rats made hypertensive by salt loading (DS or CS) were studied after 6 weeks. M-mode echocardiography revealed that left ventricular internal dimension during diastole and systole were significantly increased in D and DS, but not in C or CS. Concurrently, we found in D and DS an increase in cardiac $\beta$-myosin heavy chain, atrial natriuretic peptide, skeletal $\alpha$-actin mRNA, type III collagen, and transforming growth factor- $\beta$.
\end{abstract}

Myocardial angiotensin-converting enzyme (ACE) mRNA levels were increased while ACE2 mRNA levels were decreased in both D and DS groups. Cardiac angiotensin-1 (AT1) receptor protein levels were unchanged but the levels of phosphorylated (p) ERK and Jun- $\mathrm{NH}_{2}$-protein kinase (JNK) were increased in $\mathrm{D}$ and $\mathrm{DS}$. In conclusion, we detected early cardiac changes in diabetic rats that were unrelated to hypertension. The increase in ACE, the decrease in ACE2, and the increase in cardiac pERK and pJNK suggest an increase in free angiotensin II and AT1R signaling in the diabetic myocardium as a possible mechanism contributing to cardiac remodeling in diabetes.

Journal of Endocrinology (2008) 197, 75-83

\section{Introduction}

Heart disease, particularly coronary artery disease, is a major cause of morbidity and mortality among patients with diabetes mellitus (DM). Another important cardiovascular problem in diabetic patients, as suggested by the Framingham study, is the development of heart failure which is due to an ill-defined cardiomyopathy, even in the absence of coronary artery disease (Galderisi et al. 1991). Preclinical evidence for the occurrence of diabetic heart disease has been demonstrated in the form of both diastolic and systolic dysfunction and of structural abnormalities (Marwick 2006). In asymptomatic diabetic patients, diastolic dysfunction appears to be, in fact, very common (Zabalgoitia et al. 2001). Since hypertension is commonly associated with diabetes, however, and since hypertension per se has also been identified as an important cause of heart failure, it is difficult to identify the relative importance in the development of heart failure with diabetes and hypertension as single contributing factors.

An early phase in the development of heart failure is cardiac remodeling. Cardiac remodeling is thought to be an important aspect of disease progression in heart failure, regardless of cause (Cohn et al. 2000). It is manifested clinically by changes in cardiac size, shape, and function in response to cardiac injury or increased load. The role of the renin-angiotensin system in cardiac remodeling is exemplified by the fact that angiotensin-converting enzyme (ACE) inhibitors, which improve survival in patients with heart failure, can slow down and in some cases even reverse certain parameters of cardiac remodeling (Greenberg et al. 1995).

Angiotensin II (AngII) effects through its specific receptor (mostly AT1R) may depend on its local production. Free AngII levels are determined by the rate of its synthesis, regulated mostly by ACE, and degradation. The newly discovered ACE2 enzyme plays a role in this process (Burrell et al. 2004).

Cardiac remodeling in DM and hypertension has been less extensively investigated in comparison with post-myocardial infarction models. The aim of the present study was to investigate cardiac remodeling at the functional and gene expression level in an experimental model of DM. We studied cardiac gene expression and the activation of 'fetal' cardiac genes, which encode proteins involved in contraction, calcium handling, and metabolism (Marks 2003). Since hypertension is more commonly associated with diabetes in the clinical setting, we also tested the hypothesis that hypertension per se is an important contributor to the development of cardiac remodeling in DM.

\section{Materials and Methods}

\section{Animals}

The study was performed in the salt-sensitive hypertensive male Sabra rat model. This model consists of two strains: the Sabra hypertension-prone $(\mathrm{SBH} / \mathrm{y})$ rats that remain normotensive when fed regular diet but become hypertensive when salt 
loaded, and the Sabra hypertension-resistant (SBN/y) rats that remain normotensive not only when fed regular diet but also when salt loaded. For the purposes of the present study, only animals from the SBH/y strain were used. The animals were procured from the Israeli Rat Genome Center in Ashkelon, Israel (www.irgc.co.il).

Animals were housed in compliance with institutional regulations and in accordance with 'Principles of Laboratory Animal Care' (NIH publication no. 85-23, revised 1985) and the guidelines of the American Society of Physiology for the care of laboratory animals. Unless stated otherwise, animals were provided tap water and standard rat chow containing $0 \cdot 65 \% \mathrm{NaCl}$ (Koffolk, Tel-Aviv, Israel) ad libitum. Climatecontrolled conditions and regular-timed diurnal cycles were maintained. The local institutional review committee approved the study protocol.

\section{Study groups}

Animals were divided into four groups: Group 1 (C), nondiabetic SBH/y that were provided regular chow and thus normotensive; Group 2 (D), SBH/y-rendered diabetic rats that were provided regular chow and thus normotensive; Group 3 (CS), non-diabetic SBH/y that were salt loaded and thus hypertensive; and Group 4 (DS), diabetic SBH/y that were salt loaded and thus hypertensive.

\section{Study protocol}

Animals from the four study groups were studied over 6 weeks, during which D and DS groups were rendered diabetic, and CS and DS groups were made hypertensive. The animals ( $n=7$ per group) were killed by the end of the 6 -week study period. Cardiac function was evaluated by echocardiography on the last week of the experiment. Blood was collected from the bifurcation of the aorta, and serum was separated and frozen at $-20{ }^{\circ} \mathrm{C}$ for later measurements. The heart apex was separated and fixed in a $4 \%$ paraformaldehyde solution for histomorphological assessment (by hematoxylin/eosin, Masson, and periodic acid Schiff (PAS) stainings). The remaining heart was immediately frozen in liquid nitrogen and then at $-70{ }^{\circ} \mathrm{C}$ for later determination of mRNA and protein levels.

\section{Induction of diabetes}

DM was induced in 8-week-old male rats by i.p. injection of streptozotocin $(60 \mathrm{mg} / \mathrm{kg}$ body weight (BW) in $100 \mathrm{mM}$ citrate buffer at a $\mathrm{pH}$ of $4 \cdot 5)$. In the control group, an equal volume of buffer was injected. Only animals with serum glucose levels above $18 \mathrm{mmol} / \mathrm{l}$ and glucosuria without ketonuria were included in the study.

Diabetic animals were provided with human insulin glargine s.c. injections daily of 1 unit/day (Lantus, Aventis Pharma, $100 \mathrm{U} / \mathrm{ml})$. Urine was checked for the presence of glucose twice a week with chemstrips (Ketostix, Bayer-Ames,
UK). Whole blood glucose was measured from the tip of the tail with a glucometer when the urine glucose test was positive (Elite, Bayer Diagnostics). Food intake (energy supply) was assessed after 4 weeks. Food intake was determined by first cleaning the cages and changing the bedding. Animals were housed individually in cages and given $50 \mathrm{~g} /$ day of their standard (normal or high salt) rodent chow. The water bottle for each cage was kept full. Food placed into the feeder at the beginning and any left over at the end of each $24-\mathrm{h}$ period was weighed. Any visible food in the cage was scavenged and included in the measurements.

\section{Induction of hypertension}

Hypertension was induced in the $\mathrm{SBH} / \mathrm{y}$ immediately after the induction of DM by streptozotocin (STZ) by feeding the animals with chow containing $8 \% \mathrm{NaCl}$ for 6 weeks. This type of diet invariably leads to the development of hypertension in $\mathrm{SBH} / \mathrm{y}$.

Systolic blood pressure (BP) was measured before salt loading and at weekly intervals thereafter for a total of 6 weeks. BP measurements were performed at ambient temperature $\left(26-28^{\circ} \mathrm{C}\right)$ in awake animals by the tail-cuff method using the IITC-31 computerized BP device (IITC Life Science, Woodland Hills, CA, USA), as described previously (Yagil \& Yagil 1998).

\section{Echocardiographic evaluation}

Rats in all groups were anesthetized with tribromoethanol $200 \mathrm{mg} / \mathrm{kg}$ i.p. 2 days prior to killing. This type of anesthesia was previously shown not to depress cardiac function in rats (Schaefer et al. 2005). The rat chest was shaved and a layer or acoustic coupling gel was applied to the thorax. Two-D and M-mode echocardiography was performed by a commercially available $12 \mathrm{MHz}$ linear array transducer system (HewlettPackard, Andover, MA, USA). The animals were placed on a supine position, care was taken that the transducer had adequate contact with the amount of gel while avoiding excessive pressure on the chest. M-mode recordings were obtained of the left ventricle (LV) at the level of the mitral valve in the parasternal view, using two-dimensional echocardiographic guidance in the short-axis view. A pulsewave Doppler was used to examine mitral diastolic inflow from the apical four chamber view. For each measurement, data from three consecutive cardiac cycles were averaged. All measurements were made from digital images captured at the time of the study by the use of analysis software installed in the echocardiographic machine. The M-mode and Doppler images were obtained at a speed of $150 \mathrm{~mm} / \mathrm{s}$. LV internal dimension during diastole (LVIDD) and during systole (LVIDS) were measured. The percentage of left ventricular shortening (fractional shortening) was calculated. Based on the curve of mitral diastolic flow, peak flow velocity $(E)$ of early filling wave ( $E$ wave), peak flow velocity $(A)$ of atrial 
filling wave ( $A$ wave), $E / A$ ratio, and acceleration and deceleration time of $E$ wave were determined.

\section{Extraction of RNA}

Total RNA was isolated from frozen heart tissues by the Trireagent method (Molecular Research Center, Cincinnati, $\mathrm{OH}$, USA) according to the manufacturer's recommendation. The integrity of the RNA was assessed by visual inspection of the ethidium bromide-stained 28S and 18S RNA bands after electrophoresis through $1 \cdot 25 \% / 2 \cdot 2 \mathrm{M}$ formaldehyde gels. The quantity and quality of the total RNA extracted were evaluated at 260 and $280 \mathrm{~nm}$ u.v. wavelengths, and the optical density $260 / 280 \mathrm{~nm}$ was maintained between $1 \cdot 7$ and $2 \cdot 1$.

\section{RT-PCR}

We quantified heart $\beta$-myosin heavy chain ( $\beta$-MHC), atrial natriuretic peptide (ANP), skeletal $\alpha$-actin, type III collagen, transforming growth factor- $\beta$ (TGF- $\beta$ ), ACE, and ACE2 mRNA by RT-PCR method. RNA was converted to cDNA by adding $13 \mu \mathrm{l}$ reverse transcriptase reaction mixture, containing $1 \mu \mathrm{l}$ moloney murine leukemia virus reverse transcriptase (MMLV-RT; $200 \mathrm{U} / \mu \mathrm{l}$, Sigma), $0.5 \mu \mathrm{l}$ dithiothreitol $(0 \cdot 1 \mathrm{M}$, Sigma), $0.5 \mu \mathrm{l}$ Rase inhibitor $(40 \mathrm{U} / \mu \mathrm{l}$, Sigma), $1 \mu \mathrm{l}$ oligo-d(T) $12-18$ primer $(0.5 \mu \mathrm{g} / \mu \mathrm{l}$, Life Technologies, BRL), and $1 \mu \mathrm{l} \mathrm{dNTP}(2 \cdot 5 \mathrm{nmol} / \mu \mathrm{l}$ each nucleotide, Sigma) to each sample of RNA. The reaction tube was incubated for $1 \mathrm{~h}$ at $37^{\circ} \mathrm{C}$. The volume of each sample was then adjusted to $60 \mu \mathrm{l}$ and the enzyme was inactivated by incubation for $10 \mathrm{~min}$ at $65^{\circ} \mathrm{C}$. The resulting cDNAs were then amplified by PCR using specific primers, as shown in Table 1 . To $45 \mu \mathrm{l}$ PCR mixture containing $32 \cdot 75 \mu \mathrm{l} \mathrm{H}_{2} \mathrm{O}, 5 \mu \mathrm{l}$ reverse transcription product, $2 \cdot 5 \mu \mathrm{l} 5^{\prime}$ primer $(20 \mu \mathrm{M}), 2.5 \mu \mathrm{l} 3^{\prime}$-primer $(20 \mu \mathrm{M}), 2 \mu \mathrm{l} \mathrm{dNTP}$ $(2.5 \mathrm{nmol} / \mu \mathrm{l}$ of each nucleotide, Sigma), $5 \mu \mathrm{l}$ of $10 \times$ reaction buffer, and $0 \cdot 25 \mu \mathrm{l}$ Taq DNA polymerase (Sigma) were added. A negative control consisting of the reaction mixture without the cDNA was included in each run. Thermal cycling was initiated with incubation at $95^{\circ} \mathrm{C}$ for $5 \mathrm{~min}$ for activation of Taq DNA polymerase. After this initial step, 20-28 cycles of PCR were performed. Each PCR cycle consisted of heating at $95^{\circ} \mathrm{C}$ for $30 \mathrm{~s}$, denaturing at $56-68{ }^{\circ} \mathrm{C}$ for $30 \mathrm{~s}$, and annealing for $30 \mathrm{~s}$ at $72^{\circ} \mathrm{C}$. Incubation was prolonged by $5 \mathrm{~s}$ in each cycle. Every experiment was amplified with at least two different numbers of cycles to ensure that amplification was at the exponential phase of PCR. We found that 25-30 cycles for each target gene and $20-25$ cycles for $\beta$-actin were in this range. Under these conditions, we also found a linear dose-response of the PCR product to increase doses of cDNA. Then, $15 \mu \mathrm{l}$ of each sample containing amplified cDNA were loaded on an agarose gel $(2 \%)$ containing ethidium bromide $(0.5 \mu \mathrm{g} / \mathrm{ml})$. A DNA size marker was run on the same gel (100 bp ladder, Life Technologies, BRL). The PCR products were quantified densitometrically using Flurochem software (Alpha-Innotech, San Leandro, CA, USA). To correct differences in loading, we corrected densitometric values of each target gene cDNAs with corresponding values of $\beta$-actin cDNA and the ratios were calculated.

\section{Western blot analysis}

Heart tissue was homogenized on ice with a polytron (Kinetica, Littau, Switzerland) in lysis buffer $(50 \mathrm{mM}$ Tris ( $\mathrm{pH} 7 \cdot 4$ ), $0 \cdot 2 \%$ Triton $\mathrm{X}-100$ ) containing $20 \mathrm{mM}$ sodium pyrophosphate, $100 \mathrm{mM} \mathrm{NaF}, 4 \mathrm{mM}$ EGTA, $4 \mathrm{mM} \mathrm{Na}_{3} \mathrm{VO}_{4}$, $2 \mathrm{mM}$ phenylmethylsulphonyl fluoride, $0 \cdot 25 \%$ aprotinin, and $0.02 \mathrm{mg} / \mathrm{ml}$ leupeptine. Extracts were centrifuged for $20 \mathrm{~min}$ at $17000 \mathrm{~g}$ at $4{ }^{\circ} \mathrm{C}$ and the supernatants were collected and frozen. For the detection of heart AT1R, total and phosphoERK1/2, poly (ADP-ribose) polymerase (PARP), and total and phospho-JNK homogenates were mixed with $5 \times$ sample buffer and boiled for $5 \mathrm{~min}$. Then, $200 \mu \mathrm{g}$ portions of sample protein were loaded in each gel lane and subjected to $10 \%$ SDS polyacrylamide gel and electroblotted into nitrocellulose membranes. Blots were blocked for $1 \mathrm{~h}$ in TBS buffer $(10 \mathrm{mM}$ Tris ( $\mathrm{pH} 7 \cdot 4), 138 \mathrm{mM} \mathrm{NaCl})$ containing $5 \%$ nonfat dehydrated milk, followed by overnight incubation with the following antibodies (all diluted in TBS containing 5\% dry milk): rabbit polyclonal antibody against AT1R (Santa Cruz Biotechnology, Santa Cruz, CA, USA), rabbit polyclonal antibody against ERK (Santa Cruz Biotechnology), mouse monoclonal anti-phospho-ERK1/2 (Sigma), rabbit

Table 1 PCR-specific primers

Sense

Gene
$\beta$-MHC
ANP
Skeletal $\alpha$-actin
Type III collagen
TGF- $\beta$
ACE
ACE 2
$\beta$-Actin

\section{Gene}

Skeletal $\alpha$-actin

Type III collagen

ACE 2

\author{
CAAGTCAGCCTACCTCATGGG \\ CAAGAGAGAGCAGGACACCATCGC \\ GCGCAAGTACTCAGTGTGGATCGG \\ ATATCAAACACGCAAGGC \\ GGCACCATCCATGACATGAA \\ CACCGGCAAGGTCTGCTT \\ GTGCACAAAGGTCACAATGG \\ GACGAGGCCCAGAGCAAGAG
}

Antisense

TGACTCGAGGGTGGCACAA

TATGCAGACCCTCGGTGCTCACCT

CACCCTGCAACCATAGCACGATG

GATTAAAGCAAGAGGAACAC

CAGGTGTTGAGCCCTTTCCA

CTTGGCATAGTTTCGTGAGGAA

TGTTTCATCATGAGGCAGAGG

GGGCCGGACTCATCGTACTC 
polyclonal anti-PARP (Cell Signaling), rabbit polyclonal antibody against Jun- $\mathrm{NH}_{2}$-protein kinase (JNK; Santa Cruz Biotechnology), and rabbit polyclonal anti-phospho-JNK (Cell Signaling, Danvers, MA, USA). After washing thrice for $15 \mathrm{~min}$ in TBST $(0.05 \%$ Twin-20), the blots were incubated with a secondary anti-rabbit antibody conjugated to horseradish peroxidase or a secondary anti-mouse antibody conjugated to horseradish peroxidase for $1 \mathrm{~h}$ at room temperature, and then washed again thrice. The band antibody was visualized by enhanced chemiluminescence (Amersham, Life Sciences Inc.) and exposed to Kodak-BioMax film (Eastman Kodak). Protein expression was quantitated densitometrically using FluorChem software (Alpha-Innotech).

Apoptosis was evaluated by immunoblot detection of cleaved PARP, a well-accepted marker of apoptosis in heart tissue (Los et al. 2002), using rabbit polyclonal antibody against PARP. This antibody detects full-length PARP $(116 \mathrm{kDa})$, as well as the large $(89 \mathrm{kDa})$ and small $(24 \mathrm{kDa})$ fragments of PARP produced by caspase cleavage (Cell Signaling).

\section{Statistical analysis}

Six to eight animals were used in each experimental group. Differences within groups were determined using one-way ANOVA for non-repeated measurements followed by a post hoc analysis (Scheffe) to determine the source of significance. We set statistical significance at $P<0 \cdot 05$. Data are provided as means \pm S.E.M.

\section{Results}

\section{Blood glucose levels}

STZ induced a diabetic phenotype that is consistent with that previously described in STZ-treated animals. Average glucose levels in D and DS groups were $21 \cdot 3 \pm 1 \cdot 2$ and $20 \cdot 1 \pm 1 \cdot 8 \mathrm{mmol} / 1$ respectively. For comparison, blood glucose levels in the C and CS groups were $6 \cdot 3 \pm 0 \cdot 2$ and $6 \cdot 1 \pm 0 \cdot 2 \mathrm{mmol} / \mathrm{l}$ respectively. We did not detect ketonuria in any of the diabetic animals during the study period.

\section{Blood pressure}

During 6 weeks of salt loading, CS and DS developed hypertension, BP beginning to rise as of the third week of the study period (Fig. 1). Upon termination of the study, average systolic BP was $175 \pm 1 \mathrm{mmHg}$ in CS and $181 \pm 2 \mathrm{mmHg}$ in DS $(P=\mathrm{NS})$; in $\mathrm{C}$ rats, $\mathrm{BP}$ was $139 \pm 1 \mathrm{mmHg}$ in $\mathrm{C}$ and $128 \pm 2 \mathrm{mmHg}$ in $\mathrm{D}(P<0 \cdot 001)$.

\section{Body weight}

The diabetic animals gained less BW during the course of the study period than control animals, as shown in Fig. 2 (upper panel). Upon termination of the study, BW in D and DS was

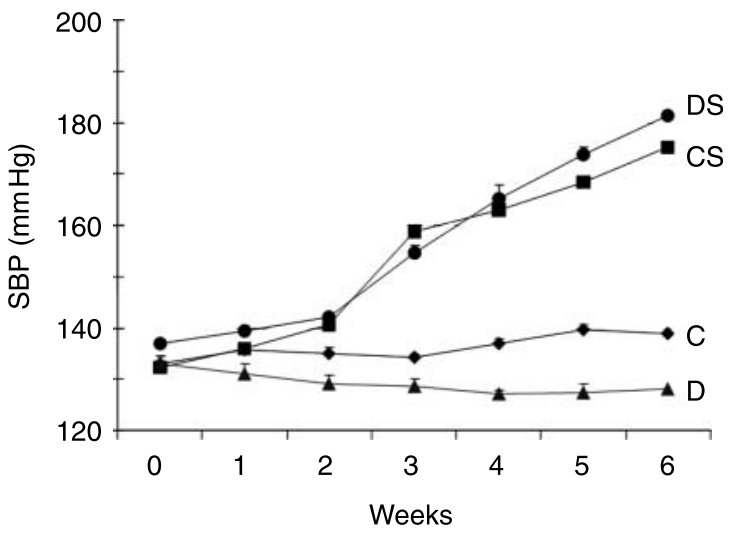

Figure 1 Tail-cuff systolic BP in controls (C), control hypertensive (CS), diabetic (D), and hypertensive diabetic (DS) animals after 6 weeks of experimentation. SBP was significantly decreased in D in comparison with $\mathrm{C}$, beginning in the second week of the experiment. SBP increased significantly in both CS and DS, but there was no difference between these two groups.

$223 \pm 15$ and $216 \pm 13$ respectively, as opposed to $295 \pm 10$ and $270 \pm 7$ in C and CS respectively. Interestingly enough, the lesser gain in weight in diabetic animals was despite greater food intake. Daily food intake, as measured 4 weeks after the induction of diabetes, was $94.7 \pm 6.9$ and $105 \cdot 3 \pm 6 \cdot 5 \mathrm{~g} / \mathrm{kg}$ in C and CS respectively $(P=\mathrm{NS})$, but was as high as $180 \cdot 4 \pm 8 \cdot 2$ and $157 \cdot 2 \pm 7 \mathrm{~g} / \mathrm{kg}$ in D and DS respectively $(P<0 \cdot 001$ versus $C)$.

\section{Heart weight}

The advent of hypertension in the non-diabetic $\mathrm{C}$ animals was associated with a $17 \%$ increase in heart weight $(\mathrm{HW})$ from $1052 \pm 38 \mathrm{mg}$ in C to $1227 \pm 42 \mathrm{mg}$ in CS $(P<0 \cdot 01)$. In contrast, in the diabetic $\mathrm{D}$ animals, the development of hypertension was not associated with any increase in HW, which was $1071 \pm 69 \mathrm{mg}$ in D and $1032 \pm 77 \mathrm{mg}$ in DS $(P=\mathrm{NS})$. However, when adjusted for BW, the HW/BW ratio was similarly and significantly elevated in all the three experimental groups when compared with the $\mathrm{C}$ group $(127 \pm 6 \%$ in CS, $132 \pm 5 \%$ in $\mathrm{D}$, and $135 \pm 6 \%$ in DS, $P<0.01$ versus $\mathrm{C}$ ), as shown in Fig. 2 (lower panel). Histological analysis of heart tissue did not reveal any significant changes between the experimental groups.

\section{Echocardiographic measurements}

Absolute left ventricular fractional shortening was normal and similar in all study groups $(66 \pm 1,64 \pm 2,61 \pm 4$, and $65 \pm 1 \%$ in C, CS, D, and DS, $P=\mathrm{NS}$ ). Absolute LVIDD values were not significantly different between study groups. However, when corrected to $\mathrm{BW}$, there was a significant increase in the LVIDD/BW ratio in the D and DS animals $(2 \cdot 6 \pm 0 \cdot 2$ and $2 \cdot 7 \pm 0 \cdot 1$ in D and DS versus $1 \cdot 9 \pm 0 \cdot 01$ and $2 \cdot 2 \pm 0 \cdot 1$ in C and $\mathrm{CS}$ respectively, $P<0 \cdot 05$ versus C; Fig. 2). A similar 

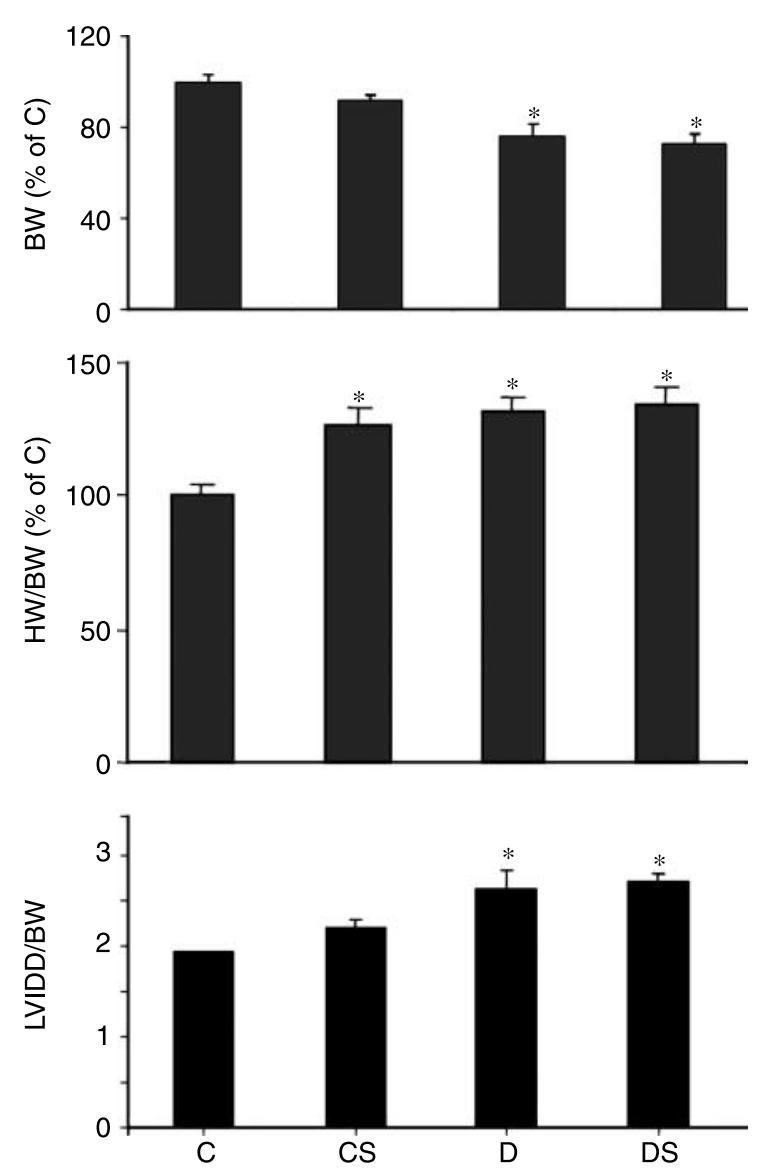

Figure 2 Body weight (upper panel), heart weight/body weight (HW/BW; middle panel) depicted as percentage of control animals; and left ventricular internal dimension during diastole (LVIDD)/BW (lower panel). ${ }^{*} P<0 \cdot 05$ versus $\mathrm{C}$ and $\mathrm{CS}$.

significant difference between the study groups was seen for LVIDS/BW $(0 \cdot 65 \pm 0 \cdot 02,0 \cdot 8 \pm 0 \cdot 07,0 \cdot 99 \pm 0 \cdot 1$, and $0 \cdot 95 \pm$ 0.09 in C, CS, D, and DS respectively, $P<0 \cdot 05$ ). There was no similar significant difference between the study groups on the LV fractional shortening, $E / A$ ratio, or acceleration and deceleration times of $E$ waves.

\section{Apoptosis}

The ratio of cardiac cleaved (89 kDa) PARP to full-length PARP (116 kDa) protein levels, as evaluated by immunoblot, was not different between the experimental groups: $102 \pm 6$, $106 \pm 12$, and $98 \pm 14 \%$ of C in CS, D, and DS respectively.

\section{Gene expression}

As shown in Fig. 3, $\beta$-MHC mRNA was $193 \pm 28$ and $178 \pm$ $23 \%$ of $\mathrm{C}$ in D and DS respectively $(P<0 \cdot 05)$; skeletal $\alpha$-actin mRNA was $209 \pm 26$ and $210 \pm 25 \%$ of $C$ in D and DS respectively $(P<0 \cdot 05)$; and ANP mRNA was $232 \pm 48$ and $230 \pm 53 \%$ of $\mathrm{C}$ in D and DS respectively $(P<0 \cdot 05)$. As shown in Fig. 4, type III collagen mRNA in CS was $157 \pm$ $4 \%$ of C, but more notably so $189 \pm 15$ and $255 \pm 19 \%$ of C in $\mathrm{D}$ and DS respectively $(P<0 \cdot 05)$. TGF- $\beta$ mRNA was increased in D to $161 \pm 19$ and in DS to $156 \pm 9 \%$ of C $(P<0 \cdot 05)$. These increases in gene expression in the hearts of $\mathrm{D}$ and DS are indicative of ongoing cardiac remodeling.

\section{The renin-angiotensin system}

As the balance between ACE and ACE2 expressions may determine the levels of free angiotensin II in the heart. ACE mRNA was increased in D to $618 \pm 91 \%$ of $C$ and DS to $569 \pm 76 \%$ of C. ACE2 mRNA was decreased in D to $66 \pm 11 \%$ of $C$ and DS to $74 \pm 10 \%$ of C. This difference was further accentuated if depicted as ACE/ACE2 ratio for each animal, as shown in Fig. 5. Cardiac AT1R protein levels were not different between the experimental groups: $92 \pm 5$, $97 \pm 5$, and $94 \pm 12 \%$ of C in CS, D, and DS respectively.

\section{Intracellular signalling}

To further elucidate the mechanism involved in the observed expression of ACE and ACE2, signaling pathways of mitogen-activated protein kinases were studied by western blot analysis of protein extracts from heart tissue. As shown in Fig. 6, cardiac phospho-ERK1/2 to ERK1/2 ratio was increased in D and DS, $1 \cdot 6 \pm 0 \cdot 2$ and $1 \cdot 3 \pm 0 \cdot 2$, respectively, compared with $0.53 \pm 0.2$ and $0.7 \pm 0.1$ in $C$ and $C S$ respectively $(P<0 \cdot 05)$. In addition, increased activation of phospho-p 46JNK and phospho-p $55 \mathrm{JNK}$ to total JNK ratio was observed in D and DS, $1 \cdot 7 \pm 0 \cdot 2$ and $1 \cdot 5 \pm 0 \cdot 15$, respectively, compared with $0 \cdot 96 \pm 0 \cdot 1$ and $0 \cdot 75 \pm 0 \cdot 1$ in $\mathrm{C}$ and CS respectively $(P<0 \cdot 05)$.

\section{Discussion}

In the present study, we found evidence for early cardiac remodeling, both in animals with DM alone and in those with concurrent DM and hypertension. Our evidence for the occurrence of cardiac remodeling consists of a relative increase in heart size, along with an increase in LVIDD and LVIDS by echocardiography. We found no evidence for increased cardiac apoptosis. However, we found an increased expression of structural myocardial response genes, namely $\beta$-MHC, ANP, and skeletal $\alpha$-actin, which have long been considered as markers of hypertrophy of the rat heart (Boluyt et al. 1995, Swynghedauw et al. 1995, Barbosa et al. 2005). We have also been able to demonstrate that DM induces similar changes in the expression of these genes without any additional effect for hypertension.

Our findings suggest that the occurrence of diabetes alone is sufficient to initiate cardiac remodeling. These findings are consistent with a previous study, during which a more prolonged period (18 weeks) of IDDM (without hypertension) 

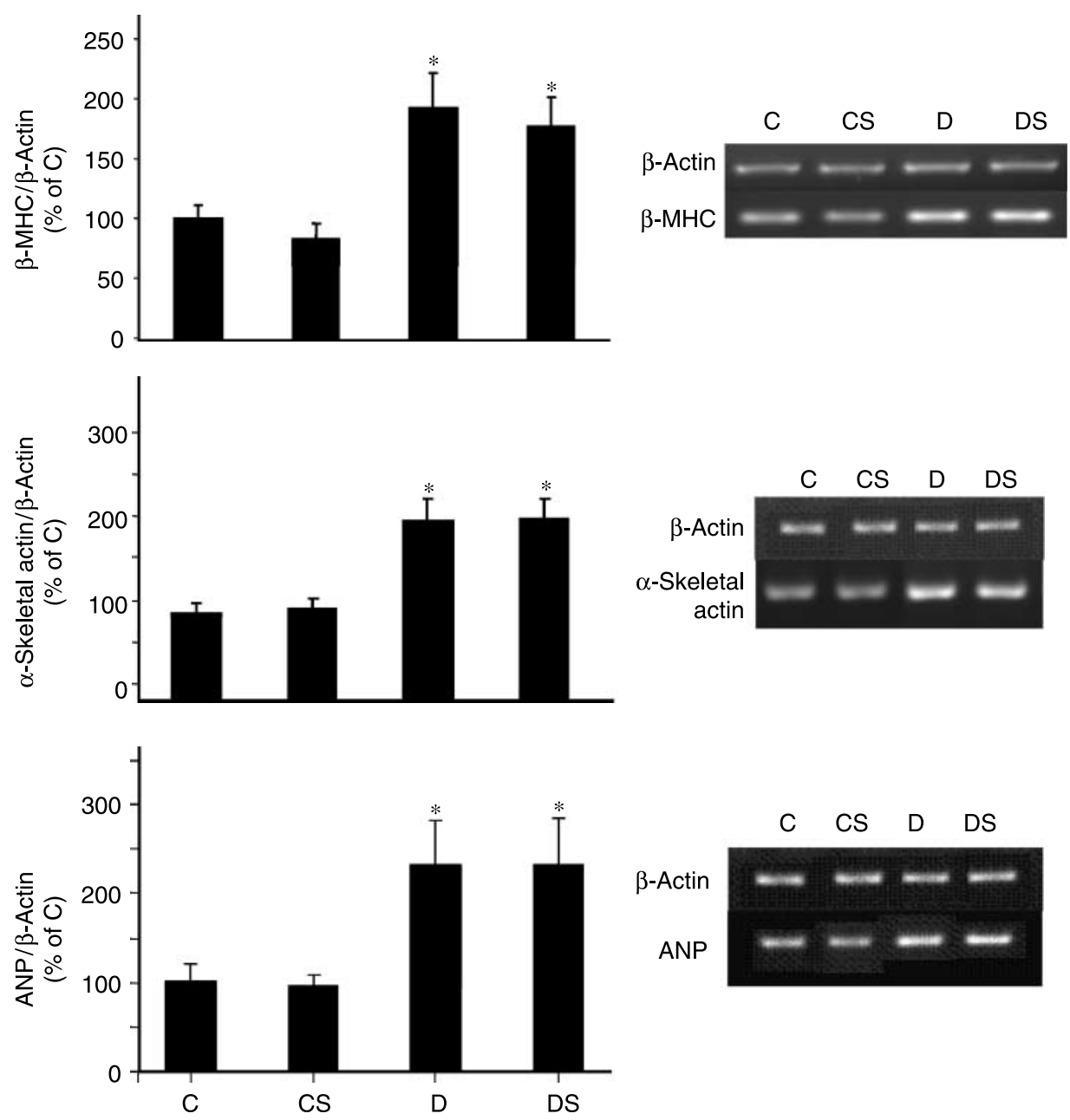

Figure 3 Cardiac $\beta$-myosin heavy chain ( $\beta$-MHC; upper panel), $\alpha$-skeletal actin (middle panel), and ANP (lower panel) mRNA levels in controls (C), control hypertensive (CS), diabetic (D), and hypertensive diabetic (DS) animals after 6 weeks of experimentation. ${ }^{*} P<0 \cdot 05$ versus $C$ and CS.

incurred not only right ventricular remodeling but also overt resting left ventricular systolic dysfunction, accompanied by pathological changes of capillaries and cardiomyocytes including actin filaments (Nemoto et al. 2006). In another study, diastolic dysfunction was detected in type I diabetic mice after 30 days of DM (Kajstura et al. 2001).

Our findings also suggest that hypertension is not required in our diabetic model for cardiac remodeling to be evoked. Hypertension has indeed been shown to be a known risk factor for cardiac remodeling in non-diabetics, leading to hypertrophy and later cardiomyocyte loss and heart failure. Previous studies have shown that 6 weeks of hypertension is sufficient to induce early cardiac remodeling (Burla et al. 2007). Our present findings indicate that 6 weeks of saltloading per se (without diabetes) and the rise in BP over 4 weeks increased the HW/BW ratio in group CS (Fig. 2), but were not enough to induce those markers of cardiac remodeling (Fig. 3) and fibrosis (Fig. 4), which were only found in both diabetic groups. These findings suggest that for early cardiac remodeling to occur, the occurrence of DM suffices without the need for hypertension to develop. However, it is quite possible that the contribution of hypertension to cardiac remodeling in diabetic patients with long-standing hypertension may become significant on the long term, as previously shown (Nagata et al. 2006).

What are the mechanisms that lead to early cardiac remodeling? Most of the information that is currently known regarding cardiac remodeling stems from the models of myocardial infarction rather than of diabetic cardiomyopathy. Sustained cardiomyocyte apoptosis, left ventricular enlargement, increased cardiac fibrosis, and enhanced profibrogenic connective tissue growth factor expression have all been demonstrated after myocardial infarction in experimental models of DM (Backlund et al. 2004). However, no information is available whether such changes also occur in DM alone, without contributing infarction. Apoptosis is 


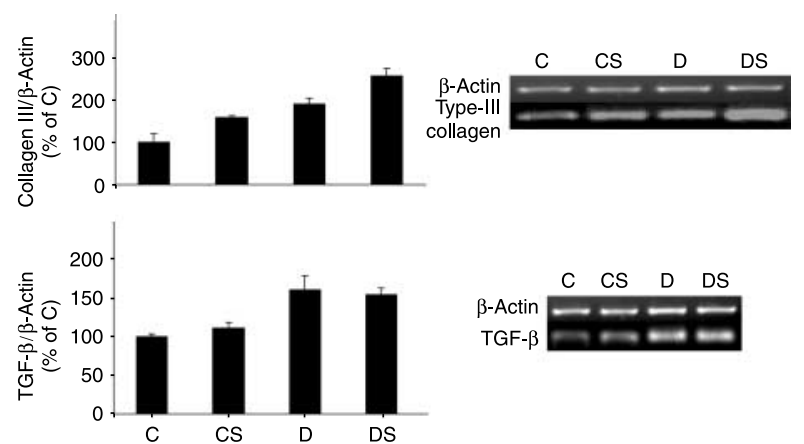

Figure 4 Cardiac type III collagen (upper panel) and TGF- $\beta$ (lower panel) mRNA levels in controls (C), control hypertensive (CS), diabetic (D), and hypertensive diabetic (DS) animals after 6 weeks of experimentation. ${ }^{*} P<0 \cdot 05$ versus $\mathrm{C}$ and $\mathrm{CS}$.

orchestrated by the proteolytic activation of cysteine proteases known as caspases. Distinct pathways of apoptosis converge for the activation of executioner caspase-3, which cleaves multiple downstream cellular targets. An important target of caspase-3 is PARP, whose cleavage and inactivation maintain
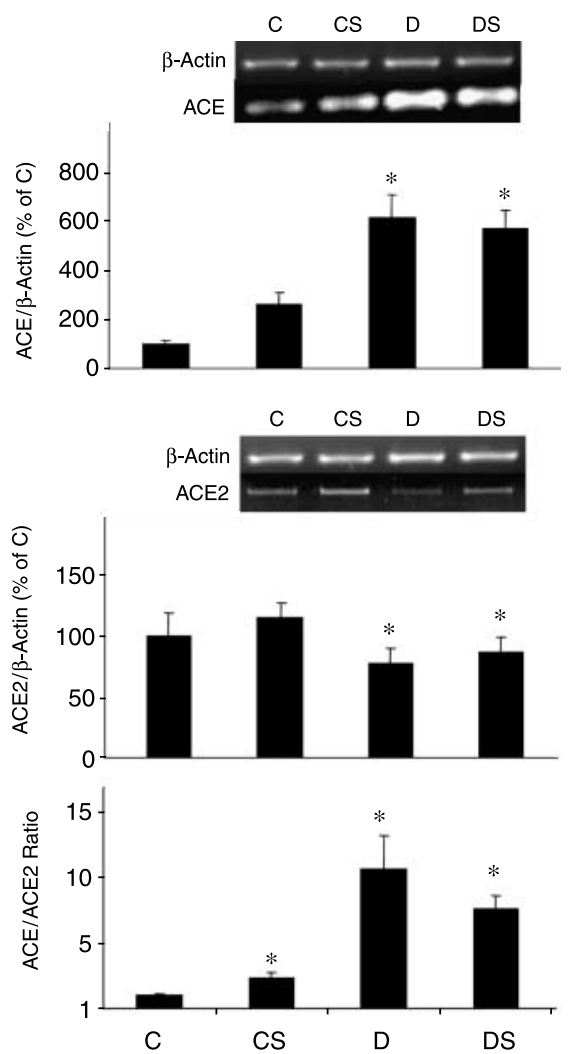

Figure 5 Cardiac ACE (upper panel), ACE2 (middle panel), and ACE/ACE2 ratio (calculated for each animal) (lower panel) in controls (C), control hypertensive (CS), diabetic (D), and hypertensive diabetic (DS) animals after 6 weeks of experimentation. ${ }^{*} P<0 \cdot 05$ versus $C$. the cellular ATP stores indispensable for apoptosis to proceed properly. The cleavage of PARP into 89 and $24 \mathrm{kDa}$ fragments inactivates the enzyme by destroying its ability to respond to DNA strand breaks, thereby preventing the loss of cellular ATP associated with PARP activation and maintaining the cellular energy essential for the execution of apoptosis. Recent evidence has emerged that apoptosis (as measured by PARP levels) is an important mechanism of cardiomyocyte cell death in conditions such as myocardial reperfusion, cardiomyopathy, and heart failure (Pacher et al. 2002). In DM, evidence for increased apoptosis in heart tissue has been shown in patients and in a model of long-term disease (Chowdhry et al. 2007). Therefore, it could be that our negative findings reflect the early remodeling changes, still not associated with increased apoptosis.

Is AngII an important culprit in diabetic cardiomyopathy? AngII could be one of the important mediators of cardiac remodeling that antedates heart failure (Fiordaliso et al. 2000). Kajstura et al. (2001) have shown an increase in cardiac angiotensinogen and renin in diabetic mice after 30 days of DM. TGF- $\beta$ may be a sign of AngII-mediated signaling in myocardium (Schultz et al. 2002). TGF- $\beta 1$ is up-regulated by AngII and induction of TGF- $\beta 1$ causes cardiac fibrosis (Lim \& Zhu 2006). JNKs are implicated in cardiac diseases and are preferentially activated by stress signals, hypertrophic stimuli such as stretch and AngII, leading to the activation of transcription factor, activator protein (AP)-1. Increased cardiac JNK and AP-1 DNAbinding activities in stroke-prone hypertensive rats were reduced by losartan. Levels of phospho-p46JNK and phospho-p55JNK were elevated in the LVs of obese mice (Zaman et al. 2004). ACEI and angiotensin II receptor blockers (ARB) decreased the activation of these JNK isoforms. As JNKs are activated by AngII and genes involved in remodeling, such as TGF- $\beta 1$, collagen, and skeletal $\alpha$-actin, have AP-1 consensus sequence in their promoter regions, it may be possible that JNK, partially mediated by AP-1, can participate in the AngII-mediated increased gene expression in obese mice. Our data consisting of increased expression of phosphorylated JNK, pERK $1 / 2$, and fibrosis-related genes (including TGF- $\beta$ ) are entirely consistent with early cardiac fibrosis driven by AngII. We could not demonstrate such histological fibrotic changes in this early stage of disease, but it cannot be ruled out that a longer follow-up study would have revealed these changes.

Although we did not measure AngII peptide levels in the present study, the low ACE2 and elevated ACE expressions in the myocardium of the diabetic animals are consistent with the elevated AngII levels. In addition, elevation of TGF- $\beta$ as well as phosphorylated ERK1/2 and JNK, both downstream signaling molecules in the AT1R signaling pathway are consistent with an increase in local AngII synthesis and action. However, more markers of specific intracellular AT1R downstream signaling need to be established to support this hypothesis. A recent study by Tsutsui et al. (2007) reports on 

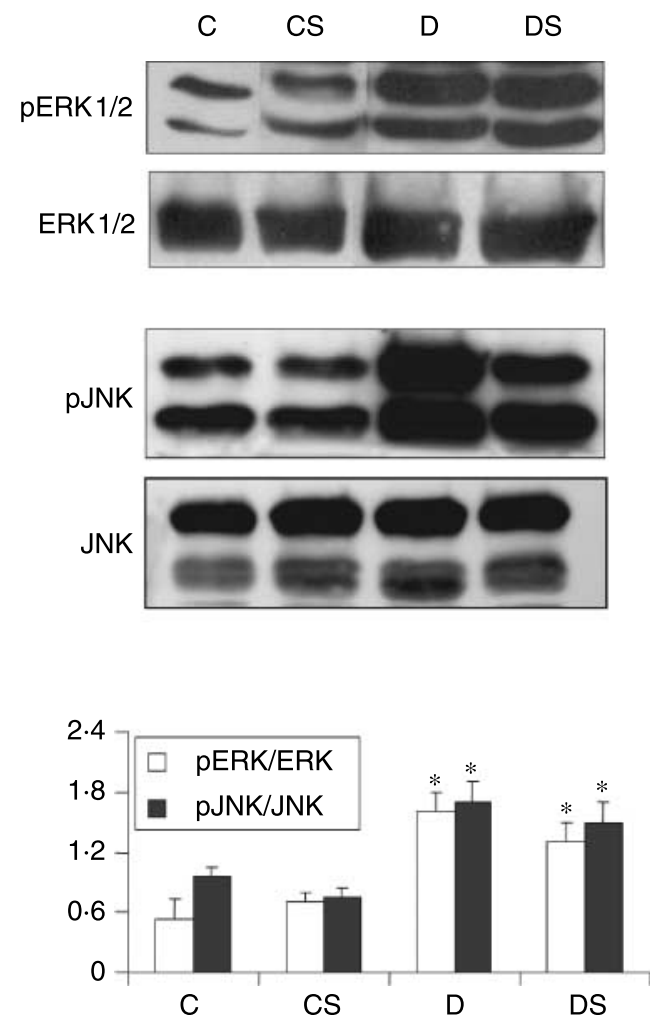

Figure 6 Western blot analysis of cardiac pERK1/2-to-ERK1/2 ratio (upper panel) and pJNK/JNK ratio (lower panel), using $200 \mu \mathrm{g}$ tissue lysates, in the control (C), control hypertensive (CS), diabetic (D), and hypertensive diabetic (DS) animals after 6 weeks of experimentation. Shown are blots representative of four independent experiments. The graph shows a densitometry analysis (represented in arbitrary densitometric units) summarizing the four independent experiments for each peptide. ${ }^{*} P<0 \cdot 05$ versus $C$ and CS.

the beneficial effects of the AT1R blocker candesartan on diastolic dysfunction as well as myocardial interstitial fibrosis and TGF- $\beta$-CTGF expression in diabetic mice. This study supports our findings on the central role of AngII in mediating the structural and functional abnormalities of the diabetic heart, in addition to the previously described role of increased oxidative stress in diabetic complications in general (Griendling et al. 1994) and the diabetic heart in particular (Fiordaliso et al. 2004).

We conclude that early cardiac remodeling occurs in the diabetic rat without the need for hypertension to develop, and that activation of the renin-angiotensin system may play an important pathophysiological role. What are the potential implications of our findings? It is already established that ACE inhibitors and ARBs reduce disease progression and mortality in patients with overt heart failure (Carr et al. 2005). Our findings suggest that blockage of the renin-angiotensin system, whether with ACE inhibitors or ARBs, might be in place in the early phases of diabetic cardiomyopathy as well, irrespective of the level of BP and even before the development of overt heart failure.

\section{Acknowledgements}

This study was supported by the grants from the USA-Israel Binational Science Foundation (\#2003055).

\section{Disclosure}

None of the co-authors has any conflict of interest that would prejudice this work's impartiality.

\section{References}

Backlund T, Palojoki E, Saraste A, Eriksson A, Finckenberg P, Kyto V, Lakkisto P, Mervaala E, Voipio-Pulkki LM, Laine M et al. 2004 Sustained cardiomyocyte apoptosis and left ventricular remodelling after myocardial infarction in experimental diabetes. Diabetologia 47 325-330.

Barbosa ME, Alenina N \& Bader M 2005 Induction and analysis of cardiac hypertrophy in transgenic animal models. Methods in Molecular Medicine 112 339-352.

Boluyt MO, Long X, Eschenhagen T, Mende U, Schmitz W, Crow MT \& Lakatta EG 1995 Isoproterenol infusion induces alterations in expression of hypertrophy-associated genes in rat heart. American Journal of Physiology 269 H638-H647.

Burla AK, Neves MF, Oigman W \& Mandarim-de-Lacerda CA 2007 Eplerenone offsets cardiac and aortic adverse remodeling in spontaneously hypertensive rats. International Journal of Cardiology 114 64-70.

Burrell LM, Johnston CI, Tikellis C \& Cooper ME 2004 ACE2, a new regulator of the renin-angiotensin system. Trends in Endocrinology and Metabolism 15 166-169.

Carr AA, Kowey PR, Devereux RB, Brenner BM, Dahlof B, Ibsen H, Lindholm LH, Lyle PA, Snapinn SM, Zhang Z et al. 2005 Hospitalizations for new heart failure among subjects with diabetes mellitus in the RENAAL and LIFE studies. American Journal of Cardiology 96 1530-1536.

Chowdhry MF, Vohra HA \& Galiñanes M 2007 Diabetes increases apoptosis and necrosis in both ischemic and nonischemic human myocardium: role of caspases and poly-adenosine diphosphate-ribose polymerase. Journal of Thoracic and Cardiovascular Surgery 134 124-131.

Cohn JN, Ferrari R \& Sharpe N 2000 Cardiac remodeling - concepts and clinical implications: a consensus paper from an international forum on cardiac remodeling. Behalf of an International Forum on Cardiac Remodeling. Journal of the American College of Cardiology 35 569-582.

Fiordaliso F, Li B, Latini R, Sonnenblick EH, Anversa P, Leri A \& Kajstura J 2000 Myocyte death in streptozotocin-induced diabetes in rats in angiotensin II- dependent. Laboratory Investigation 80 513-527.

Fiordaliso F, Bianchi R, Staszewsky L, Cuccovillo I, Doni M, Laragione T, Salio M, Savino C, Melucci S, Santangelo F et al. 2004 Antioxidant treatment attenuates hyperglycemia-induced cardiomyocyte death in rats. Journal of Molecular and Cellular Cardiology 37 959-968.

Galderisi M, Anderson KM, Wilson PW \& Levy D 1991 Echocardiographic evidence for the existence of a distinct diabetic cardiomyopathy (the Framingham Study). American Journal of Cardiology 68 85-89.

Greenberg B, Quinones MA, Koilpillai C, Limacher M, Shindler D, Benedict C \& Shelton B 1995 Effects of long-term enalapril therapy on cardiac structure and function in patients with left ventricular dysfunction. Results of the SOLVD echocardiography substudy. Circulation 91 2573-2581.

Griendling KK, Minieri CA, Ollerenshaw JD \& Alexander RW 1994 Angiotensin II stimulates NADH and NADPH oxidase activity in cultured vascular smooth muscle cells. Circulation Research 74 1141-1148.

Kajstura J, Fiordaliso F, Andreoli AM, Li B, Chimenti S, Medow MS, Limana F, Nadal-Ginard B, Leri A \& Anversa P 2001 IGF-1 overexpression inhibits the development of diabetic cardiomyopathy and angiotensin II-mediated oxidative stress. Diabetes 50 1414-1424.

Lim H \& Zhu YZ 2006 Role of transforming growth factor-beta in the progression of heart failure. Cellular and Molecular Life Sciences 63 2584-2596. 
Los M, Mozoluk M, Ferrari D, Stepczynska A, Stroh C, Renz A, Herceg Z, Wang ZQ \& Schulze-Osthoff K 2002 Activation and caspase-mediated inhibition of PARP: a molecular switch between fibroblast necrosis and apoptosis in death receptor signaling. Molecular Biology of the Cell 13 978988.

Marks AR 2003 A guide for the perplexed: towards an understanding of the molecular basis of heart failure. Circulation 107 1456-1459.

Marwick TH 2006 Diabetic heart disease. Heart 92 296-300.

Nagata K, Obata K, Xu J, Ichihara S, Noda A, Kimata H, Kato T, Izawa H, Murohara T \& Yokota M 2006 Mineralocorticoid receptor antagonism attenuates cardiac hypertrophy and failure in low-aldosterone hypertensive rats. Hypertension 47 656-664.

Nemoto O, Kawaguchi M, Yaoita H, Miyake K, Maehara K \& Maruyama Y 2006 Left ventricular dysfunction and remodeling in streptozotocininduced diabetic rats. Circulation Journal 70 327-334.

Pacher P, Liaudet L, Mabley J, Komjáti K \& Szabó C 2002 Pharmacologic inhibition of poly(adenosine diphosphate-ribose) polymerase may represent a novel therapeutic approach in chronic heart failure. Journal of the American College of Cardiology 4 1006-1016.

Schaefer A, Meyer GP, Brand B, Hilfiker-Kleiner D, Drexler H \& Klein G 2005 Effects of anesthesia on diastolic function in mice assessed by echocardiography. Echocardiography 22 665-670.

Schultz Jel J, Witt SA, Glascock BJ, Nieman ML, Reiser PJ, Nix SL, Kimball TR \& Doetschman T 2002 TGF-beta1 mediates the hypertrophic cardiomyocyte growth induced by angiotensin II. Journal of Clinical Investigation 109 787-796.
Swynghedauw B, Besse S, Assayag P, Carre F, Chevalier B, Charlemagne D, Delcayre C, Hardouin S, Heymes C \& Moalic JM 1995 Molecular and cellular biology of the senescent hypertrophied and failing heart. American Journal of Cardiology 76 2D-7D.

Tsutsui H, Matsushima S, Kinugawa S, Ide T, Inoue N, Ohta Y, Yokota T, Hamaguchi S \& Sunagawa K 2007 Angiotensin II type 1 receptor blocker attenuates myocardial remodeling and preserves diastolic function in diabetic heart. Hypertension Research 30 439-449.

Yagil Y \& Yagil C 1998 Does the Sabra hypertension-prone rat represent a model of salt or mineral mineralocorticoid sensitivity? Journal of Hypertension 16 1481-1484.

Zabalgoitia M, Ismaeil MF, Anderson L \& Maklady FA 2001 Prevalence of diastolic dysfunction in normotensive, asymptomatic patients with wellcontrolled type 2 diabetes mellitus. American Journal of Cardiology $\mathbf{8 7}$ 320-323.

Zaman AK, Fujii S, Goto D, Furumoto T, Mishima T, Nakai Y, Dong J, Imagawa S, Sobel BE \& Kitabatake A 2004 Salutary effects of attenuation of angiotensin II on coronary perivascular fibrosis associated with insulin resistance and obesity. Journal of Molecular and Cellular Cardiology 37 525-535.

Received in final form 22 January 2008

Accepted 7 February 2008

Made available online as an Accepted Preprint 7 February 2008 